\title{
NC3A AS A PLATFORM TO SUPPORT C4ISR CAPABILITIES DEVELOPMENT FOR THE COMPREHENSIVE APPROACH
}

\author{
Velizar SHALAMANOV
}

\begin{abstract}
A model for cooperative capability development among NATO and Partner Nations in support of the Comprehensive Approach for crisis management is presented. The 'Comprehensive C4ISR Approach' (Command, Control, Communications, Computers, Intelligence, Surveillance, Reconnaissance) through NC3A could be a useful instrument, not only for operationalizing the Comprehensive Approach for crisis management, but also for change management across all of NATO, positioning the agency as a platform for collaborative capability development and service provision. It will help in: addressing the requirements of the Integrated Security Sector as a whole (more than just those of defence structures); providing coordinated support throughout the full life cycle of C4ISR capabilities, and combining diverse funding streams. This approach is supported by several newly available tools and venues for coordination. These could help match top-down requirements with "bottom-up" solutions to strengthen interoperability in secure environments for many players - NATO, Partner Nations, and other international organizations, including those associated with the EU or the UN. In turn, this approach could lead to a platform, based on Network of Excellence on C4ISR, although full realization of the Network will require significant organizational innovation and change management.
\end{abstract}

Keywords: Capability Development, Emerging Security Challenges, Enterprise Architecture, ISAF, IED, common funding.

\section{Introduction: Emerging Security Challenges and Comprehensive Approach to Crisis Management}

In April 2008 NATO agreed to develop and implement a Comprehensive Approach to address new kinds of complex security challenges. In 2010 a new division on Emerging Security Challenges (ESC) was established within the NATO International staff. This period also has seen an increase in the speed and scope of change, uncer- 
tainty and complexity in the security environment, influenced by the global economic crisis, among other things. These were reflected in NATO's new Strategic Concept, adopted at the Lisbon Summit in 2010.

These challenges can be addressed in several ways: through improved strategic assessments, more use of dynamic planning and appropriately focused exercises, developing more joint capabilities through "bottom-up" engagement, better coordination of efforts among NATO bodies and Member Nations and outreach to Partner Nations and organizations (especially the EU and the UN). Collectively, these would go a long way towards the adoption of a 'Smart Defence' approach. ${ }^{1}$

More and more, individual Nations and the Alliance as a whole will look to combine military approaches with "whole of government" and "whole of issue" engagement. This will strengthen the vision for applying a Comprehensive Approach to all emerging security challenges, outside of Article 5 on collective defence. Military and civilian bodies need to be provided with Civil-Military Network Enabled Capabilities (NEC) that are genuinely effective. This will have implications for the new NATO Defence Planning Process, Operations Planning and Command \& Control (C2). With the shift to an "incident management" model, intelligence, surveillance and reconnaissance (ISR) capabilities include more and more joint and interagency components. More exercises and experiments are needed to gain a better understanding of the Comprehensive Approach, and how to operationalize it.

The Comprehensive Approach requires effective interaction and information sharing between civil and military organizations. Such interactions can occur in many functional areas such as:

- Civil-Military Cooperation and Coordination (CIMIC/CMCO) activities performed before, during and after a crisis;

- Analysis, monitoring and control functions that routinely are performed jointly, e.g. for criminal/terrorist investigations or border control, as well as during responses to civil and humanitarian emergencies and the management of their consequences;

- Protection of high visibility event, such as G8 meetings, Olympic Games, etc., and security of critical infrastructure (e.g. for production and or delivery of energy or food.

The need for this sharing has been shown across a range of recent events: disaster relief operations, complex emergencies and crises. Such civil-military interactions vary in intensity and quality, ranging from cooperation to coordination to coexistence. 
In the context of these emerging security challenges, this paper suggests that the development of a Comprehensive C4ISR (C2, Communications, Computing, ISR) Approach in the NATO Consultation, Command and Control Agency (NC3A), and execution in cooperation with other agencies, can be a powerful instrument for change management in NATO and the larger security community around the Euroatlantic allies. This approach can improve civil-military interactions, which are key elements in operationalizing the comprehensive approach for crisis management. In this way NC3A evolves as a platform for capability development and, along agency reform, the new Communication and Information agency will cover service provision trough the same approach. It is about IT governance ${ }^{2}$ in time of change ${ }^{3}$ in order to implement effective strategy, ${ }^{4}$ based on good experience of NC3A in last 15 years in using strong portfolio management. ${ }^{5}$

\section{Capability Development Challenges and the Evolving Comprehensive C4ISR Approach}

The three main pillars of the Comprehensive C4ISR Approach were explained by NC3A in 2009. ${ }^{6}$ They are:

- Support to requirements from all elements of the integrated security sector on national, regional and NATO levels;

- Cooperative support from across NATO over the whole life cycle of C4ISR capabilities;

- Integration of all possible funding mechanisms in support of the "Smart Defence" concept.

These first pillar reflects the concept of integrated security sector and "whole of government” approach to security and by including industry and non-governmental organizations as well as other players moves to state to embrace the "whole of the issue” approach in addressing the emerging security challenges.

Second aspect is related to the requirement to have seamless capability management throughout all the phases of the life cycle - "from cradle to grave." This is extremely important because inefficiencies and uncalculated costs appear when we miss to plan holistically and a lot of delays appear because of transfer of authorities phase after phase.

Last pillar provides best use of all funding mechanism and it is of critical importance because of the eligibility aspects of budgeting projects as well as to provide maximum flexibility in the times of financial constraints. Customer funded regime for NATO and national agencies is the base for using these multiple funding mechanisms with high degree of transparency, accountability and integrity of the process. 
These three pillars are considered as a base for the Agencies reform in NATO as it was decided in Lisbon, 2010.

Several kinds of cross-cutting changes will be needed if these pillars are to be integrated into effective operational capabilities:

- Doctrines, organizational arrangements and tools must reflect the Comprehensive Approach in addressing emerging security challenges and crisis management;

- Strategic assessments and scenario-based planning need to consider diverse problems and approaches, particularly comprehensive C4ISR capabilities;

- Governance of ICT (Information and Communications Technology) must support the development of comprehensive C4ISR capabilities, including models for multinational cooperation among Allies, Partner Nations and even non-governmental entities.

All this will require closer cooperation between operational, transformational and implementation authorities in the framework of the political guidance provided by the North Atlantic Council, when it comes to NATO capability development process.

Serious study also is required on the application of advanced ICT to support the implementation of the Comprehensive Approach, as well as the development of capabilities based on technologies such as:

- Smart sensors, particularly for identification of unconventional threats, including Improvised Explosive Device (IED) scanners and sniffers;

- Situational Awareness and Civil-Military User-Defined Operational Pictures (UDOP), rather than just singular Common Operational Pictures (COP), including information sharing and knowledge management in complex environments;

- Collaborative/Coalition decision making and C2 tools, particularly tools supporting incident management;

- Core services and network management for seamless secure communication in diverse environments, including cloud computing and grid technology;

- Distributed modelling and simulation, training, advanced distance learning, etc.

Most of these technology areas are covered in the NC3A catalogue of expertise, but in closer cooperation with industry and national agencies it is possible to extend the base for supporting capabilities development for the Comprehensive Approach in more innovative ways. 
The three pillars of the Comprehensive C4ISR Approach are supported by several instruments. One is the NC3A Catalogue of C4ISR expertise, developed for the first time in 2010. It covers areas of support to the capability development process that are provided by the Agency. ${ }^{7}$ Two interrelated models of cooperation (bilateral and multinational) can be developed, based on the content of the Catalogue. They draw on the corporate knowledge and tools of the Agency to support capability development for both Nations and organizations. The model of bilateral cooperation is supported by the framework C4ISR Memorandum of Understanding between Nation and NC3A. The multinational cooperation development model ${ }^{8}$ is based on operational activities, with more than ten projects on-going and about same number that just started, or soon to be launched. In both models the Agency is a facilitator within the NATO environment and provides technical support as an executive agent for Nations to develop and acquire required critical C4ISR capabilities, involving academia and industry as well as government sources.

Such approaches require a genuinely adaptive organization which is sensitive to the customer environment. ${ }^{9}$ To improve its agility, NC3A initiated an annual Chief Information Officers (CIO) conference in 2010. This complements existing industry conferences in fall, with separate meeting in spring, partnering with AFCEA (formerly the Armed Forces Communications-Electronics Association) and the US National Defense University's information resource-focused iCollege. Going forward, the NATO Defence College (NDC) in Rome and the George C. Marshall Center in Garmisch-Partenkirchen may be involved to help develop NATO and Partner Nations' leaders. Both the CIO and Industry conferences are supported by legal instrumentsBasic Ordering Agreements (BOA) for industry and framework Memoranda of Understanding with Nations - to enhance information sharing, longer term planning and also quick reaction in emergencies. Thus, the three pillars of the Comprehensive C4ISR Approach are supported by models of bilateral and multinational cooperation, with the Catalogue to explain available capabilities and twinned conferences to link the NC3A better with both customers and Industry.

After initial introduction as a concept in November 2011 there is already list of evidences of successful development and implementation of the Comprehensive C4ISR Approach.

First aspect to be mentioned is the eightfold increase of the number of MoUs with nations for two years, covering NATO members and partner nations. More important is that more than 10 new MoUs are under negotiation and transition from separate projects to programme of work (POW) on yearly and multiyearly basis with $\mathrm{MoU}$ nations is under way. With these developments introduction of country pages / fact sheets, internal cooperation development portal and external web site on opportunities for nations to be further developed as electronic platform for capability develop- 
ment for nations with the agency (agency as a platform) created knowledge environment for enhanced cooperation.

As mentioned above, in addition to NATO members work with partner nations and contact countries (Sweden, Finland, Australia, New Zealand) started as well as interest from Qatar, UAE, Republic of Korea was manifested.

MoUs are mostly focussed on relations with respective MoDs and other ministries, but step by step another network is under development - around introduction of Cooperation agreements with public R\&D institutions (Fraunhofer - Germany, Bulgarian Academy of Sciences, CNIT - Italy, TUBITAK - Turkey to be mentioned).

In parallel to the support to mostly military customers, the Agency is developing relations with civilian structures in the field of security (NATO IS, national MoI and cyber security institutions, EU) and is currently running several projects under NATO Civil budget (Afghanistan SILK, Portal for SPS) funding.

In 2011, working very closely with the NATO Advisory team from NATO Defense Policy and Planning Division, NC3A is using Kosovo Trust Fund to support the development of Management Information System for the Ministry of Kosovo Security Forces, that is seen as a very good example of capacity development and involvement in transition - something to come up in Afghanistan and may be in Libya.

One of the successful efforts that have produced tangible results in 2011 is the one of using multinational funding under NATO IS for the NATO-Russia Cooperative Airspace Initiative.

Having good experience through common funding for regional air defence projects at Poland, Czech Republic, Hungary we now support to regional approach in the Balkans (BRAAD - Balkan Regional Approach to Air Defence), led by NATO IS and in very close cooperation with NAMSA, NCSA and NACMA - our sister agencies.

Furthermore, since 2009 NC3A is exploring by invitation of existing regional defence cooperation processes support to SEDM (South astern Europe Defence Ministerial), Nordic Defence Cooperation (NDC) and DACH format between Germany, Austria and Switzerland. We look forward to be of use for Baltic Defence Cooperation (BDC) and the UK-France defence cooperation.

With NATO enlargement and many active partner countries, the Agency is involved in consulting the development of national capacity in portfolio/project/contact management - to mention the example of Bulgaria.

It was a practice, but now even more in the focus along development of smart defence concept we work on transition from common funded to multinational funding projects - to mention Afghanistan Mission network (AMN), Integrated Command and Control (ICC) and efforts for Cyber Defence (CD), Counter IED (C-IED), Civil-Military In- 
teroperability (CMI), Training, Exercises and Experiments (T\&EE), Allied Defence Analysis \& Planning Toolset (ADAPT).

Comprehensive C4ISR Approach gave start to the NC3A Catalogue of C4ISR expertise, evolving to a catalogue of tools and in parallel we have started the transition from independent tools to mission oriented suits, to mention AMN as an example.

Implementation of the Comprehensive C4ISR Approach provided for activation of revolving fund in support to cooperation development and very strong link of Agency Strategic Plan with NATO Strategic Concept and other strategic documents as well as with national strategic documents.

As a result initial efforts around the Catalogue in the new context of cooperation development facilitate the definition of "NC3A (Communications \& Information Agency) as a platform for collaborative capability development and service provision" model.

Future implementation of the Comprehensive C4ISR Approach will require a large effort by both NATO and Nations. But NC3A, with a team made up of representatives from both NATO sponsoring accounts and participating Nations, decided to emphasize a "bottom up" approach to capability development related to the initiation of several critical bilateral and multinational projects (in the areas of C-IED, Cyber Defence, Defence Support to Civilian Authorities and the NATO Exercise Toolbox, for example). ${ }^{10}$ These efforts need to be paralleled by common funded capabilities to achieve greater interoperability for complex operations more quickly and at lower cost.

This combination of top-down and bottom-up approaches to capability development, and integration of common, joint, multinational and national funding, could allow NC3A to help strengthen interoperability in secure environments for many players NATO and Partner Nations, as well as other international organizations, such as those associated with the EU or the UN.

Instead of establishing a stand-alone CoE (Centre of Excellence) for Comprehensive Approach, operationalizing the concept in this way could let the Alliance realize its first truly distributed Network of Excellence. C4ISR would play a critical role in such a network and NC3A could be a hub where many interrelated efforts could be maintained through virtualization.

\section{NC3A as a platform for collaborative capability development in C4ISR area}

The NC3A is a NATO agency that shares the legal personality of NATO. Its charter was approved by the North Atlantic Council (NAC). The agency is 100 percent funded by its customers. NC3A is part of the NATO C3 Organization, along with the 
NATO C3 Board and NATO Communication and Information Systems (CIS) Services Agency (NCSA).

NC3A's mission is to enable NATO's success through the unbiased provision of comprehensive C4ISR capabilities. This mission is achieved within the framework of the strategic plan, the current version of which is available online. ${ }^{11}$ Each plan is approved by the NC3 Board.

NC3A has significant expertise in the Comprehensive C4ISR Approach, ranging from defence planning to combat support. Coherence and interoperability are overseen by a strong Chief Technology Office, while the principal limit to implementation lies in the capacity of the Directorate of Production. All areas of expertise are covered in the NC3A Catalogue. The first edition was distributed in 2010 and the next version is being developed in close coordination with Nations.

This diverse C4ISR expertise, together with competence in program, project and financial management, as well as excellent relations with stakeholders in the NATO environment, positions the Agency well to propose solutions to Nations on a bilateral basis, or to facilitate multinational projects. ${ }^{12}$ A comprehensive, multinational C4ISR roadmap is being prepared for presentation to the NATO Task Force on Multinational Approaches to Capability Development.

New projects are initiated based either on requirements defined by NATO HQ and Strategic Commands or on requests from Nations and other organizations. To support these, based on unique corporate C4ISR knowledge, NC3A can plan and offer to Nations either the use of NATO-off-the-shelf (NOTS) tools on a bilateral basis or the development of cooperative capabilities through new multinational projects. These can be based either on NOTS or NOTS' customization, according to the customer's requirements. NC3A's Annual Report for 2010 shows more than 500 diverse projects under development or implementation. ${ }^{13}$

These bottom-up approaches provide opportunities to use existing tools and Research and Development results, which are available under the common funded, top-down capability development process, to inform Nations (including industry) about "low hanging fruit" that can be implemented by either national or multinational approaches.

The CIO and Industry conferences, mentioned earlier, are used to inform the user community and companies about these opportunities and to facilitate the exploitation of these solutions for delivering critical capabilities effectively.

Smart Defence will require a new generation of organizational innovation in NATO, the EU and Nations (government, academia, industry) to be able to benefit from such opportunities. This is a serious change management challenge that will influence the 
culture of the organizations involved, ${ }^{14}$ but it is necessary if the Alliance is really committed to developing network enabled capabilities for the Comprehensive Approach.

From the capabilities prospective, the next challenge is to transition Expert Domain Tools (toolboxes) to Mission-Oriented Suites. The best recent example is the operationally driven Afghanistan Mission Network (AMN). In the past, the Bi-Strategic Commands Automated Information System (Bi-SC AIS) served as a good example on which to base lessons learned. Efforts to achieve an Integrated Air Defence System, and now to add Theatre Ballistic Missile Defence capabilities, are other examples of mission-oriented approaches to integrating C2 systems. With the transition to the Comprehensive Approach a new goal is to define suites of capabilities for Civil Military complex operations. This not only includes understanding how to use civilian capabilities in support of military operations. It also means redefining the toolbox for Defence Support to Civilian Authorities missions in Crisis Operations, as well as for support to transition operations. This can be a vehicle for closer cooperation between NATO and the EU, as well with the UN. There is much to learn from National experiences, ${ }^{15}$ but NATO and its Agencies also must engage to support this part of the capability development process if the Comprehensive Approach is to be implemented successfully on an international level. This is a management challenge of a different magnitude.

Complex operations are, as a rule, coalition based, with the involvement of many diverse international organizations, so pure national approaches are not enough. Success in such operations must be built on a process of capability development, where cooperation on technical and industrial levels paves the way to operational excellence.

In additional to developing more technical capabilities, there is a growing need to cooperate in the areas of planning, architectures and exercises. Therefore, the Comprehensive C4ISR Approach focuses on capabilities that enhance the environment for interagency and multinational planning, using the architectural approach and support exercises to train with the new capabilities, new concepts and plans in integrated scenarios. In practice we have CWIX as experimental exercise, CMX as crisis management exercise, new NATO Defence Planning Process to include crisis management capabilities and new scenarios, derived from the New NATO Strategic Concept as a base for this approach.

Important trends of the last three years (2009-2011) is the eightfold increase in the number of MoUs with Nations and transition to annual / multi year (MY) POW (programme of work). Based on this change the amount of work done for nations on bilateral basis tripled and the level of effort to support MN projects doubled. Together with the transition from mostly release of operational tools, training and consultancy, 
support to acquisition to the more complex projects for development of mission oriented suits (like Afghanistan Mission Network national extensions for example, complex air defence solutions, support to national effort of institution building as establishing CoE or program offices) there is a clear evidence of the shift of paradigm for the Agency from pure common funded implementation body to the platform to link these common funded projects with national / multinational efforts in the framework of defence planning process, including for partner nations and in coordination with the EU (using NATO-EU capabilities planning group). This shift is outlined on Figure 1.

Another dimension of this shift of paradigm to NC3A as a platform for collaborative capability development / service provision ${ }^{16}$ is seen in the integration of capabilities and processes for experimentation, exercises, planning around shared operational scenarios and using common infrastructure, legally established through the framework of DNBL (distributed networked battle lab) as shown of Figure 2.

\section{Bi-lateral / Multilateral Cooperation Development (Support to Nations, based on Common funded experience)}

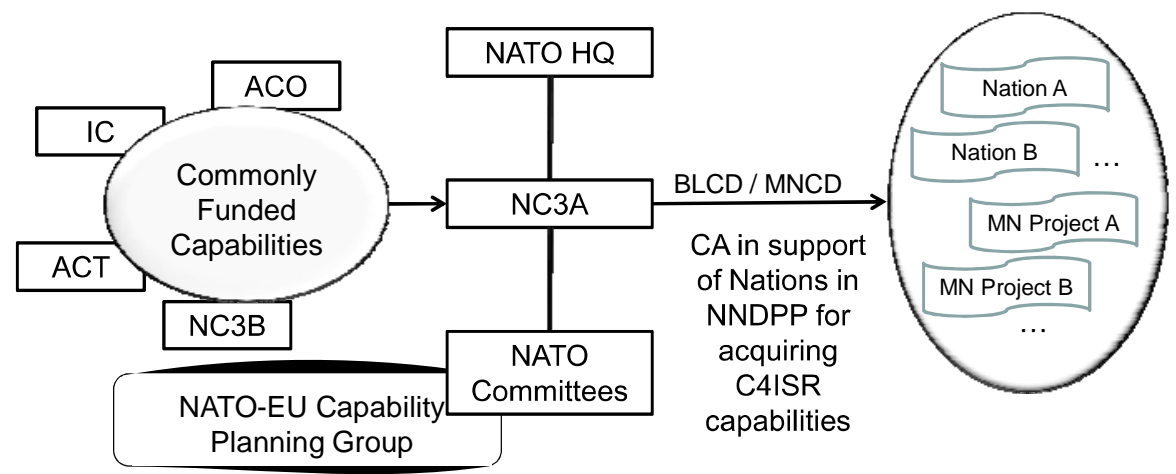

Promote the use of NATO common funded tools, and propose added value services to support interoperability in secure environment: provide solutions (with industry), testing, validation, training, ...

Figure 1: Shift of paradigm in NC3A support to capability development. 


\section{NC3A/C\&IA as a platform for C4ISR capabilities development in support to NATO and Nations}

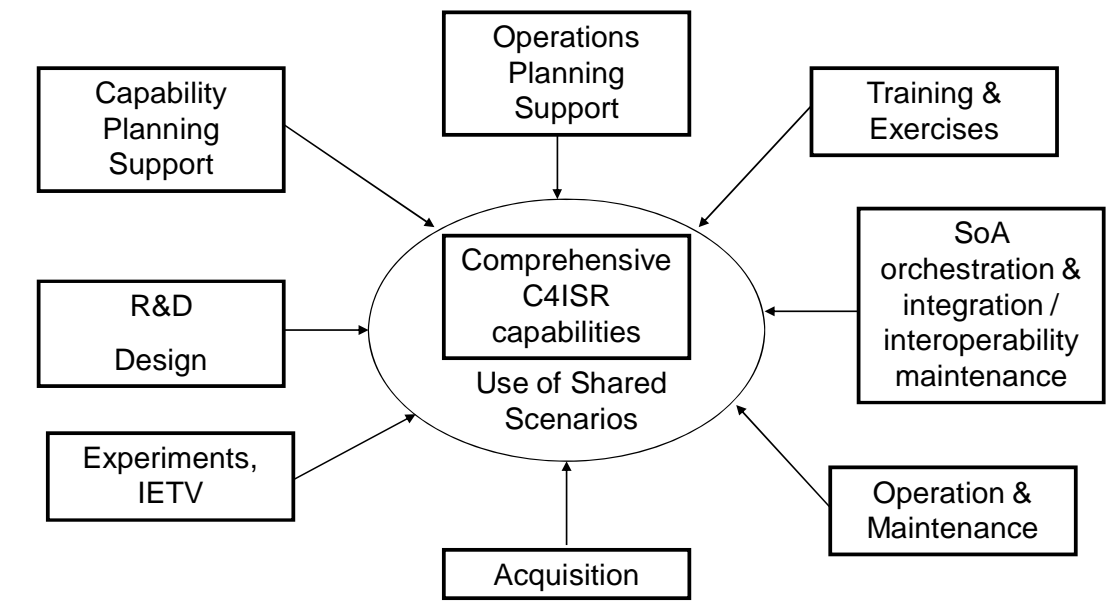

Governance / Financing, Architecture / Technology, Management

Figure 2: Integrated support to capability development in NC3A.

In order to support this shift the step of critical importance was the establishment of DSA NN (director sponsor account NATO \& Nations) in very close cooperation with LA (legal advisor), FC (financial controller), SM (strategy manager), PR (public relations), CTO/DSA ACT (chief technology officer/ director sponsor account ACT), DOP (director of production), DOR (director of resources), DAcq (director of acquisition), coordinated by the COO (chief operating officer) and DSA ACO/NIP (director sponsor account ACO and NNEC implementation program - with focus on main programmes management in the Agency). Currently the processes of internal coordination are discussed and documented in order to move to a system of their electronic support that will be presented to the customers - HQ, NCS (NATO Command Structure), NFS (NATO Force Structure), NATO agencies/bodies, nations (both members and partners) and external organizations as EU, UN, OSCE and other eligible customers with real web-based environment for capability / service orchestration, supported by the NC3A as a platform. Initially it will require more front-end focus on CRM (customer relationship management), cooperation development, strategic assessment / planning in order to shape the environment and influence the internal 
process to reflect this new environment of "intelligent customers," but later when these processes are automated, based on knowledge management solutions, it will be very easy to provide high quality of support to the intelligent customers with less people and by deeper involvement of the customers in orchestrating of the solution needed.

One of the most interesting areas for testing this approach is the area of Comprehensive Approach to Crisis Management, because it is the area of great potential of cooperation between nations (both members and partners), between NATO and EU (of course EU and US), as well as strategic relations NATO-India, NATO-China in addition to already established NATO-Russia and NATO-Ukraine formats. This area is a great opportunity to develop innovative models for PPP - especially between NATO and industry, including in the area of outsourcing and joint effort to critical infrastructure protection, not excluding cyber defence. One possible architecture of NC3A as a platform in this area is outlined on Figure 3.

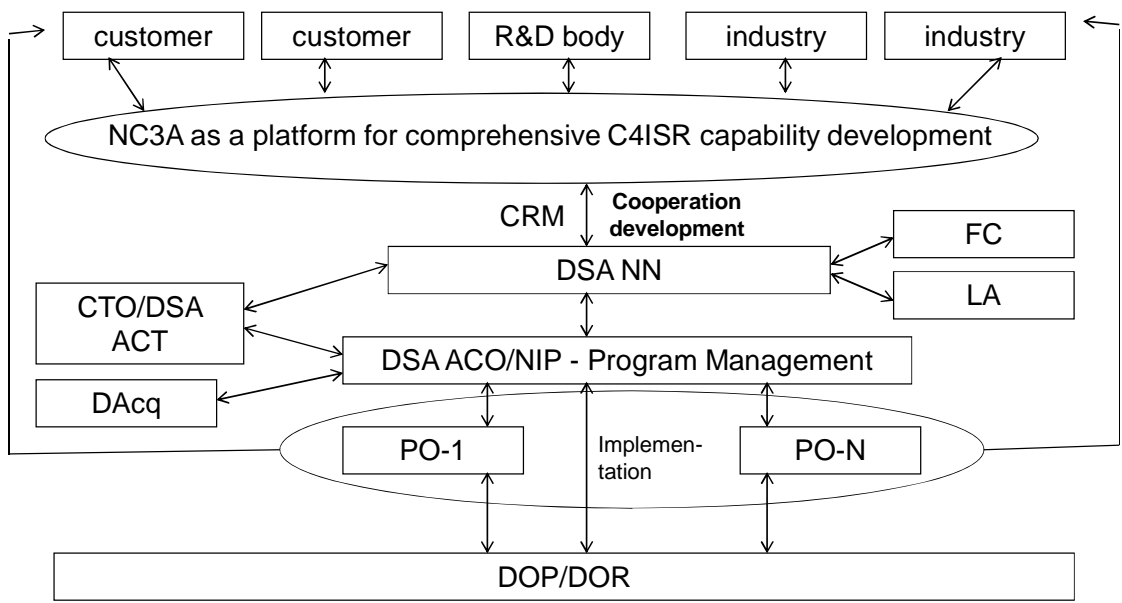

COO - coordination of the whole operation

Figure 3: NC3A as a platform for collaborative comprehensive C4SIR capability development (using current elements in the new architecture). 


\section{Current experience in C4ISR support to the Comprehensive Approach to Crisis Management / Disaster Relief}

As presented above, NC3A is implementing a really holistic approach to C4ISR capability development by supporting the processes of capability planning and operations planning, through involvement in exercises and experiments - all based on shared operational scenarios. At the same time developed capabilities are really comprehensive and in support of the comprehensive approach to operations: from communications and ISR networks, through C2 applications (including in logistics and medical support area), force / parameter protection solutions, and down to support of building civilian capabilities in convoy tracking, emergency management, management information systems, internet access for universities for example.

Currently the adaptation of TOPFAS (main NATO tool for operations planning) is under way to support the Comprehensive Approach and at the same time the use of TOPFAS for strategic assessment tasks is further developed.

It is under discussion to integrate TOPFAS with the JDARTS as a tool for capability planning and to adapt to the Comprehensive Approach as well.

TOPFAS is well linked with Integrated Command \& Control family to include the development of integrated command and control for crisis management - JPECT. Successful multinational, integrated C2 projects, and existing tools such as JPECT (Joint Planning Execution and Control Tool), as well as the implementation of network and core service experiences from the Afghanistan Mission Network (AMN), form the basis for transferring information to other elements of the C4ISR suite tailored the Comprehensive Approach. When it comes to the Civil-Military C2 domain we could refer to Multinational Maritime Information Services (MIS - a joint ACTNC3A initiative to support civil-military cooperation at sea) and NATO-Russia Council Cooperative Airspace Initiative (NRC CAI - a system for NATO-Russia cooperation in air security and safety). In this area, Sweden's initiative on Crisis NEC as an extension of a joint NATO - Swedish experiment in 2008, where NC3A will have an opportunity to work with the European Defence Agency (EDA) under the leadership of NC3B/Sweden, is another good model for the development of capabilities in support of the Comprehensive Approach.

The development of capabilities for logistics (including movement management, convoy tracking, assets tracking) along the LOGFAS family and special focus on introducing of medical support information systems is another area of support to the comprehensive approach.

Crisis management exercises in many countries (Bulgaria, Netherlands, Sweden, as well as multinational - Phoenix 2010, Viking 2011, etc.) and experimentation events 
as CWIX are a very good venue to prove the value of agency's toolset. Ongoing preparation of a multinational project on the NATO EXercise Toolbox (NEXT) in the framework of DTE (Distributed Training and Exercises) initiative of ACT, with special focus on Comprehensive Approach-type scenarios will use the above lessons to contribute to the critical capabilities for experimentation and training - so important to support any transformational / change management process.

Some specific capabilities for operationalizing the comprehensive approach are under development through separate multinational projects, such as the ones started in the area of C-IED and in large JISR for civil security. The C-IED multinational project demonstrates the important role that NC3A plays in support to NATO efforts, from clearing house analysis to direct implementation of agreed national and multinational projects. This area is a model for the transfer of operational lessons learned from Afghanistan into the development of critical capabilities that were identified during the Lisbon summit.

C-IED is one example of the innovative use of JISR (Joint ISR) technologies to address emerging challenges related to terrorism. It is an example of capabilities that are required not only by the military, but also by other security sector organizations. The multinational project known as MAJIIC (Multi-sensor Aerospace-Ground Joint Intelligence Surveillance and Reconnaissance Interoperability Coalition) is considered a model for the power of cooperative development of capabilities with the direct involvement of national industries within flexible frameworks. This will enable adaptation and allow deployment of these capabilities to support scenarios for the Comprehensive Approach to Crisis Management. These technologies serve as a basis for development of perimeter protection capabilities from military bases to civilian airports.

Another multinational initiative in the field of cyber defence is providing an example of the use of ACT-funded research in establishing the foundation, not only for common funded critical capability as NCIRC (NATO Cyber Incident Response Capability) — one of the top priorities from the Lisbon Summit—but also for effective bilateral and multinational projects between NC3A and Nations in support of larger efforts to protect cyber space. Cyber defence, being a new area, shows how important it is to have an agreed technical framework and a maturity model as a basis for coordinated efforts in a multinational environment. Support to cyber defence exercises and experiments is another example of the use of NC3A as platform for comprehensive capability development in the areas of emerging security challenges.

Operations such as those in Kosovo and Afghanistan (and sooner or later for any other NATO operation, even support to the transition in Libya if called for) eventually will require support of transition phase, which includes the transfer of authority to national/regional civilian powers. This phase creates specific requirements for ca- 
pability development for the national/regional authorities and the transfer of some of the expeditionary capabilities to these organizations. Several projects, such as support to the NATO Training Mission in Afghanistan (NTM-A), providing Internet access to Afghan universities (SILK - Afghanistan), consultations to support the development of a management information system for the Ministry of Kosovo Security Forces, and many others, are examples of the diversity of follow-on support efforts needed to operationalize the Comprehensive Approach. Development of MIS for mKSF, provision of Internet access to Afghani universities, development of a map to predict and assess flooding, CIS support to PRTs and OMLTs as well as training of police in Afghanistan are just examples of projects that build bottom up capacity to support transition.

The challenge of operationalizing the Comprehensive Approach from the capability development point of view is focused mostly on interactions among many different capabilities from a variety of organizations (civil and military), as well as the transition from expeditionary capabilities to local capabilities.

A short review of possible C4ISR-related areas in support of the Comprehensive Approach shows that the main challenge is, and will be, less in the area of technology and even architectures than in the governance, financing and management of such projects, programmes, portfolios in genuinely international environment. This must involve the members and partners of NATO, in cooperation with industry, academia and even non-governmental organizations.

\section{Conclusions: Operationalizing the Comprehensive Approach}

NC3A's experiences so far, especially in the development and implementation of the Comprehensive C4ISR Approach, show that it is possible to provide bottom up / capability-driven ways to operationalize emerging security and defence strategies. Bottom-up capability development, service provision and overall life cycle support for NATO, Nations and partner organizations, using different funding mechanisms and involving industry, is practically the only way to support the Comprehensive Approach effectively. It is worth noting that good cooperation in capability development probably also will facilitate cooperation in planning and operations for crisis management.

There are limits to top-down solutions for implementing the Comprehensive Approach, simply because of the very dynamic decision-making environment at those levels. Bearing in mind that NC3A addresses the first " $\mathrm{C}$ " - the Consultations among Nations - the Agency is well positioned to integrate bottom-up developed capabilities in ways that could support top-down consultations and decision making before the activation of an ad-hoc "coalition of the willing" of nations and organizations to address the problem through the Comprehensive Approach. Real success could be 
achieved when C4ISR arrangements in such coalitions are able to support effective implementation of political and resource decisions. In this sense, development and implementation of the NATO Comprehensive C4ISR Approach, initiated by NC3A, is of significant importance to the operationalization of the Comprehensive Approach to Crisis Management.

NC3A is only one element of the greater Network of Excellence required to implement the Comprehensive Approach, but it is a critical one for the development of the required capabilities. With Agency reform within NATO and potential cooperation between NATO and the EU in capability planning / development, maintaining an adequate mandate will be very important for the future Communications and Information construct. The construct must cover the full range of C4ISR expertise required by an integrated security sector both through the integration of life-cycle support to C4ISR capabilities and also through customer funding. The goal is to develop the comprehensive management of a program of work for NATO, Nations, groups of Nations and other organizations, including the United Nations and the European Union.

For the development of Comprehensive Approach capabilities, it will be especially useful to investigate the modalities of the NATO C4ISR Integration Fund (NCIF), initially proposed by NC3A as a model to support partners and transition countries when NATO Nations have clear interests in developing their capabilities for the future joint operations. ${ }^{17}$ The NCIF is just a construct to provide an environment to use the NC3A expertise and corporate knowledge to serve the interests and goals of contributing Nations. Adopting of the NCIF model in a truly comprehensive way-outside the limitations of eligibility and consensus-is very important for crisis management scenarios and the development of new partnerships. Of course it will not compromise the essence of Article 5 support that the Agency provides under common funding projects, and on all key decisions nations will consult at the North Atlantic Council level before engaging the Agency as an executive body for any project outside the purely NATO environment.

Agency reform is focussed on savings, but first of all its priority is on finding effective and efficient ways to deliver NEC-related outcomes. It recognizes the importance of organizational innovation and required cultural change. ${ }^{18}$ The development of capabilities for the Comprehensive Approach could help make the future Communications and Information Agency into a genuinely adaptive organization, ${ }^{19}$ but they also could become a driving force for transformation across NATO and Nations by encouraging the combination of efforts for collective defence, crisis management and partnership as key missions of the Alliance. 
Bottom up steps to support the comprehensive approach to crisis management through comprehensive approach to C4ISR capability development / service provision is building a model for the Agency as a platform for collaborative capability development / service provision.

Currently this model consists of Comprehensive C4ISR Approach, Catalogue of expertise and tools, Model for MN capability development, Model of C4ISR Integration Fund, set of MoUs/POW with nations / organizations, internal portal for the Agency on cooperation development with nations and organizations, external web page in the Agency web site on opportunities for nations.

The next step will require closer work with CTO, DOP, FC, LA to develop multilayer web portal for different customers to cooperate with the Agency in defining (even online) contracts for capability development / service provision, based on the existing environment and its adaptation / upgrade.

To meet face to face with customers, several front offices could be established geographically and for different segments of users. Annual Chief Information Officers conference is providing a venue for discussion of trends and strategic objectives for development of the Agency as a platform for the collaborative capability development.

\section{Notes:}

1 NATO Secretary General Rasmussen stated that the financial crisis calls for "smart defence, which ultimately promotes more coherence and effectiveness in defence spending in our member states." See "Secretary General stresses need for smart defence spending with Hungarian and EU leaders," NATO Newsroom, 23 February 2011, www.nato.int/cps/en/ SID26821FF1-8799271F/natolive/news_70768.htm.

2 Peter Weill and Jeanne Ross, IT Governance: How top performers manage IT decision rights for superior results (Boston, MA: Harvard Business School Press, 2004).

3 Daryl R. Conner, Managing at the Speed of Change (New Your, NY: Random House, 2006).

${ }^{4}$ Yves Doz and Mikko Kosonen, Fast Strategy: How Strategic Agility will Help You to Stay Ahead of the Game (Philadelphia, PA: Wharton School Publishing, 2008).

${ }^{5}$ Pat Durbin and Terry Doerscher, Taming Change with Portfolio Management: Unify Your Organization, Sharpen Your Strategy and Create Measurable Value (Austin, TX: Greenleaf Book Group Press, 2010).

${ }^{6}$ NC3A, NATO Comprehensive C4ISR Approach (Brussels: NC3A Graphics, November 2009), available at www.nc3a.nato.int/About/Pages/Publications.aspx.

7 NC3A, NC3A Catalogue of Expertise, 1st ed. (Brussels: NC3A Graphics, May 2010), available at www.nc3a.nato.int/About/Pages/Publications.aspx. 
${ }^{8}$ NC3A, NC3A Multi National Cooperation Development (Brussels: NC3A Graphics, October 2010), available at www.nc3a.nato.int/About/Pages/Publications.aspx.

${ }^{9}$ Scott Moreland and Scott Jasper, "Adaptive Organizations: Maintaining Competitive Advantage by Exploiting Change," in Crosscutting Issues in International Transformation, ed. Derrick Neal, Henrik Friman, Ralph Doughty, and Linton Wells II (Washington D.C.: The Center for Technology and National Security Policy, National Defense University, 2009), 249-270.

${ }^{10}$ See the accompanying articles by Franco Fiore and Frederic Jordan and Geir Hallingstad in this volume of Information \& Security.

${ }^{11}$ NC3A, NC3A Strategic plan 2011-2013 (Brussels: NC3A Graphics, July 2010), available at http://www.nc3a.nato.int/About/Pages/Publications.aspx.

${ }^{12}$ NC3A, NC3A Multi National Cooperation Development.

${ }^{13}$ NC3A, NC3A Annual report 2010 (Brussels: NC3A Graphics, March 2011), available at http://www.nc3a.nato.int/About/Pages/Publications.aspx.

${ }^{14}$ Derrick Neal and Louise Carver, "Delivering Network-Enabled Capability: The Importance of Innovation in Delivering Culture Change," in Crosscutting Issues in International Transformation, ed. Derrick Neal, Henrik Friman, Ralph Doughty, and Linton Wells II (Washington D.C.: The Center for Technology and National Security Policy, National Defense University, 2009), 55-74

${ }^{15}$ Linton Wells II and Walter Christman, "Transformational Initiatives in Civil-Military Operations STAR-TIDES and Maritime Environments," in Crosscutting Issues in International Transformation, ed. Derrick Neal, Henrik Friman, Ralph Doughty, and Linton Wells II (Washington D.C.: The Center for Technology and National Security Policy, National Defense University, 2009), 87-102.

${ }^{16}$ Jan Baan, Business Operations Improvement: The new Paradigm in Enterprise IT Cordys Holding B.V., 2010), E-book available for download at www.cordys.com/cordyscms_com/download_ebook.php.

${ }^{17}$ NC3A, NATO C4ISR Integration Fund (Brussels: NC3A Graphics, June 2010), available at www.nc3a.nato.int/About/Pages/Publications.aspx.

${ }^{18}$ Neal and Carver, "Delivering Network-Enabled Capability: The Importance of Innovation in Delivering Culture Change.”

${ }^{19}$ Moreland and Jasper, "Adaptive Organizations: Maintaining Competitive Advantage by Exploiting Change.”

Dr. VELIZAR SHALAMANOV is Director Sponsor Account NATO \& Nations at the NATO Consultation, Command and Control Agency. He is a change management and IT governance specialist, combining governmental experience (including as a former Deputy Minister of Defence of the Republic of Bulgaria, 1998-2001) with sound theoretical knowledge and background in operations research and security studies, specializing in security sector reform, primarily from organizational management perspective and use of IT. Dr. Shalamanov has considerable expertise in leading and participating in national and international research and change management teams. He is member of the International Advisory Board of the Geneva Centre for the Democratic Control of Armed Forces (DCAF), member of the Editorial Board of Information \& Security: An International Journal, Chairman of George C. Marshall Association - Bulgaria, and member of the AFCEA Brussels chapter.

E-mail: Velizar.Shalamanov@nc3a.nato.int. 